\title{
FENOMENOLOGÍA DE LA VIOLENCIA DEL SIGLO XXI EN EL SALVADOR: LA JUVENTUD SIN LUGAR
}

\author{
PHENOMENOLOGY OF THE VIOLENCE OF THE 21ST CENTURY IN \\ EL SALVADOR: YOUTH WITHOUT PLACE
}

\author{
María del Carmen García Aguilar \\ Iván Francisco Porraz Gómez
}

Recibido: 18/02/2018 - Aceptado: 12/07/2018

\begin{abstract}
Resumen
Este trabajo explora los vectores básicos de la fenomenología de la violencia contemporánea en El Salvador, se centra particularmente en los jóvenes y en las representaciones que construyen las instituciones y la sociedad sobre ellos; también se toman en cuenta aquellos discursos que los jóvenes definen para sí mismos y para los otros. Se sostiene que los jóvenes, como categoría analítica y normativa, encaran el desafío de su realidad: "sin lugar", pero sujetos a representaciones que los coloca como sujetos del mal. El objetivo de esta comunicación es tensar estas representaciones desde el "habla" de los jóvenes que figuran su propio mundo e irrumpen los discursos e imágenes que reducen su existencia juvenil a las pandillas.

Palabras clave: Violencia, jóvenes, representaciones, Estado, globalización, seguridad nacional.

Abstract

This paper explores the basic vectors of the phenomenology of contemporary violence in El Salvador, focusing particularly on young people and the representations on which their institutions and society are built, taking into account both the discourses that young people use to define themselves and those they present to others. It argues that young people, as an analytical and normative category, face a challenging reality: without a defined place of their own, they are often subject to the discourses of others that locate them as subjects of evil. The objective of the essay is to more tightly bind the representations of young people's reality taken from own speech to the world that they build for themselves, and break through the discourses and images that would reduce their youthful existence to gangs.
\end{abstract}

Keywords: Violence, young boys, representations, States, Globalization, national security. 


\section{Introducción}

La construcción de los jóvenes como categoría analítica y como campo de intervención institucional, ${ }_{1}^{1}$ desde dónde definir las maneras de ser joven, es un hecho relativamente emergente en El Salvador; nace, como proyección futura, del marco político democrático definido en los Acuerdos de Paz (1992). No obstante, su representación como "amenaza social" se difumina casi de inmediato, con lo cual se cierra todo discernimiento que llevara a ponderar los marcos contextuales que los colocó a la sombra del hacer social y político; con ello, rehabilitar una categoría analítica y política que posibilitara la restitución de derechos y el sentido de "promesa" y de "conflicto", la cual encarna su naturaleza social y etaria, esto es, su "ubicación en el margen de una fase inicial de separación (de la vida privada de la familia) y otra de agregación (a la vida de adulto)" (Urteaga 33-34).

Entender el significado y los sentidos de ser joven en El Salvador es el propósito de esta investigación. Su estructura expositiva y analítica se organiza en cuatro apartados: el primero indaga sobre su constitución, desde sus expresiones y condiciones históricas y cotidianas, y desde los planos de las representaciones sociales e institucionales que les dota de concreción e idealidad. En el segundo se analizan estas representaciones latentes en la configuración de la retórica, las imágenes y el lenguaje que habla de la violencia juvenil, al hacer énfasis en el juego discursivo que oculta la violencia sistémica que las hace posible. El tercero intenta poner en juego las tensiones de las representaciones y las formas laberínticas y paradojales del Estado y la sociedad, con el discurso que los jóvenes elaboran para sí y para los otros. Son sus relatos, trágicos e inciertos, los que intentan hacer inteligible el mundo "sin lugar" que habitan; sin embargo, como el titilar de las luciérnagas, pareciera que construyen esa "política menor" que insinúa Agamben, aunque, en sus límites, solo sea para vivenciar el reclamo de que "las bestias y el mal están en otra parte". El último apartado es una reflexión somera sobre los vectores invisibilizados que, como fondo oscuro, son los productores de una violencia que globalizada se hace más particular y más cruel.

\section{Jóvenes y violencia en El Salvador. Continuidades y rupturas}

En 2015 El Salvador registró una tasa de homicidios de 102.9 por cada 100 000, la más alta del mundo, de Latinoamérica y de la región Centroamericana. Aunque en el año 2016 se observa una significativa disminución, la tasa de homicidios, la cual fue de 80.9, mantiene al país en los primeros lugares (InSight Crime). Los esfuerzos por explicar esta "barbarie" y destrozo moral, han pecado de generalidad o de infinita parcialidad; con lo cual terminan por hacerla inexplicable. Los estudios, más cercanos a los hechos concretos, sostienen que se está frente a "un nuevo patrón de violencia", estructurado por un "proceso de mayor presencia y control territorial y social de los 
grupos delictivos". Es una violencia que se expande, con el consecuente aumento del número de víctimas, el registro inédito de nuevos rostros de la violencia y la "confrontación armada entre el Estado y los grupos delictivos" (INCIDE 7; Kinosian et al. 4).

No obstante, en la mayoría de las lecturas pesa una sentencia consensuada y paradojal que sostiene, por un lado, que detrás de la violencia están los jóvenes, reducidos a pandillas y maras, segregados en prácticamente todos los departamentos de El Salvador, convertidos hoy en verdaderos campos de batallas; y, por otro lado, con menor fuerza, sostiene que los jóvenes resultan ser los más afectados, las víctimas, son principalmente hombres jóvenes, entre veinte y treinta años. Es notorio que las representaciones e imágenes portadoras de la primera corresponden a los actores locales, gobierno, políticos, empresarios y sociedad, en tanto que las segundas provienen mayormente de agencias públicas internacionales de instituciones universitarias y de organizaciones no gubernamentales internas y externas.

Estas lecturas plantean la necesidad de reconstruir el lenguaje y de desmontar lo que está detrás de cada una de las palabras que configuran el campo semántico de la violencia, para, con la misma sencillez de las palabras otras, registrar una realidad que "es lo que es": una construcción de poder. En términos llanos, entender la violencia en El Salvador exige cuestionar lo que el sentido común, político y mediático da por hecho, obviando o banalizando todo fundamento histórico-social. Sin la comprensión de esta violencia histórica y contextual, no es posible entender la articulación entre violencia y jóvenes, hoy hegemónica en El Salvador.

El acierto de que los jóvenes son lo que su sociedad define como tal (Cruz 27) propicia la primera pregunta: ¿qué son los jóvenes para la sociedad y las instituciones salvadoreñas? Sin ser sorpresa, se descubre la inexistencia histórica de un campo de estudios y de políticas propias para ese segmento etario definido como juventud. Se explica no solo por la continuidad de la centralidad del mundo rural en las sociedades del sur, cuyo marco relacional e intersubjetivo compromete a temprana edad la incorporación de sus miembros a la reproducción familiar y a las responsabilidades comunitarias, sino, fundamentalmente, por el constructo particular de una sociedad que se insinuó "moderna", construida por la fuerza de una economía que impuso formas brutales de explotación y expulsión a los habitantes nativos.

El proceso de independencia que devino en la emancipación de España y en la construcción de la República trajo consigo el legado del conservadurismo de las élites políticas y económicas, lo cual no solo mantuvo la estructura social colonial, sino también, desde el espacio privilegiado de la construcción constitucional, pudo modular el Estado decimonónico de acuerdo con esa herencia colonialista, visible en la continuidad de lo que le fue propio; esto es, la violencia desestructuradora de "los límites entre la vida y la muerte" y, con ello, "el silenciamiento del cuerpo" (Mbembe 14).

Esta continuidad en la forma de dominación mancomunada, entre poder económico y político, no estuvo exenta de contradicciones en el seno de las elites. 
En las primeras décadas del siglo $\mathrm{XX}$, cuando el café ya era sustento vital de la economía y soporte de la clase propietaria, las contradicciones surgieron no solo de los intentos políticos de democratización que amenazaban con dislocar el sistema oligarca, sino también de la amenaza de articulación de las masas trabajadoras al comunismo internacional.

El Salvador, que ya registraba un movimiento obrero, con la formación de federaciones y sindicatos, se abre a una dictadura militar que, con el mismo basamento constitucional liberal democrático, va a gobernar durante media década. El montaje del comunismo internacional con el beneplácito del poder estadounidense hace de la dictadura en El Salvador una sociedad violentada en sus mínimos derechos vitales, pero, interiormente confrontada con la población mayoritaria y los movimientos de escala mundial, como los movimientos antifascistas, dictatoriales y autoritarios; los costos entrañaron recurrentes contradicciones internas entre las élites económicas y el poder político alcanzado por los militares (Granados).

La particularidad deElSalvador, con respecto a los otros países deCentroamérica, es, para Flores y otros historiadores y analistas políticos, la configuración de ese Estado autoritario-militar. Este último interioriza la violencia sistémica que exige un terreno al margen de reglas legales e institucionales, pero cuya posibilidad se dio por los intereses geopolíticos y estratégico militares de Estados Unidos, los cuales en el marco de la Guerra Fría se sustentan en la doctrina de "seguridad nacional" (Flores 57).

Salvaguardado por la nervadura del poder estadounidense, y después de gobiernos directos de la oligarquía cafetalera, el poder militar hecho gobierno tuvo dos condiciones previas: el golpe de Estado de 1931 y el asesinato de entre 15000 y 30000 personas, en el socavamiento de la rebelión de 1932 (Alvarenga 57). "Con la matanza, el Estado se propuso eliminar a los comunistas y a sus aliados", el Partido Comunista salvadoreño se erige en el enemigo a vencer, adelantándose, con su abierto anticomunismo, al arsenal ideológico y político de la Guerra fría, declarada por Estados Unidos: "el anticomunismo de la centroamericanización de la guerra fría encontró un terreno propicio en el que confirmó los temores que venían de décadas anteriores" (Flores 71). Desde entonces los militares fueron poder político:

Las fuerzas armadas salvadoreñas son únicas en el continente americano, porque han logrado institucionalizar a través del partido y mediante promociones de la escuela militar, una participación política. Es obvio que el costo social de esta participación ha sido alto, pero ello, no desdice que se han institucionalizado al interior de la estructura nacional del poder (Flores 72).

El agotamiento de la retórica de "defender el orden interno al precio de la democracia” y la prédica del "anticomunismo como ideología de la represión”, devino, ya en los años sesenta y setenta, en una "democracia de fachada" que culmina en una etapa preinsurreccional: un "clima de guerra civil fue envolviendo a todos los actores 
en un camino sin regreso" (Torres-Rivas 111). A la luz del tiempo, y de la analítica política del autor citado, la complejidad de la guerra civil tornó insuficiente la misma confrontación ideológica dualista; no obstante, en su evaluación, a más de 25 años de Los Acuerdos de Paz, no puede pasar inadvertida la injerencia norteamericana en una guerra formalmente interna. Su ayuda posibilitó que el número de activos del ejército salvadoreño pasara de 14 a 45 mil hombres activos, en tanto el Frente Farabundo Martí para la Liberación Nacional (FMLN), que inicia la lucha con 2000 hombres en 1981, termina con cerca de 10000 una década después. Torres-Rivas concluye:

De no haber recibido inmediata ayuda norteamericana en proporciones masivas, no hubieran sido capaces de resistir la insurrección popular. La ayuda de 35 millones (1981) subió a 67.5 (1982), 72.5 (1983) y 150.4 millones al año siguiente hasta alcanzar casi 700 millones y un centenar de asesores (Torres-Rivas 115).

Sin el dominio estadounidense tampoco se explica que El Salvador iniciara la guerra civil con un gobierno provisional que, ante la exigencia del senado estadounidense de la "legalización" del poder, esto es, de elecciones constitucionales, culminara con el triunfo de una coalición de extrema derecha liderada por Roberto D’Aubuison, joven oficial fundador de la Alianza Republicana Nacionalista (ARENA), al que le seguiría, en 1984, después de 55 años, el primer gobernante civil de la oposición, en la figura de José Napoleón Duarte (Torres-Rivas 120). ${ }^{2}$ La guerra civil salvadoreña, que hizo de la violencia el magma de la sociedad, como un todo, culminaría en un horizonte político ya proyectado en la arena de la formalización política. Su marco referencial ineludible fue la democracia representativa y su vector liberal, sin sopesar ningún principio de independencia nacional y ningún desafío implicado en la superación de su creciente atraso y desigualdad social. Para Torres-Rivas:

Lo alcanzado en la mesa de negociaciones no tiene nada en común con los principios politicos que, años atrás, acompañaron a los levantamientos insurgentes. Está probado que en el transcurso de la guerra, todo cambia, incluyendo los ideales. Se tranzó la guerra, se olvidaron los programas, se negoció la democracia liberal. Los vivos quedaron con la memoria herida, que vale para no olvidar a los muertos (127).

¿Y los jóvenes? Como en muchos países y regiones del Sur, en El Salvador el tránsito de una sociedad colonial a una sociedad moderna tornó inamovible el uso, el control y la administración de la población, independientemente de la edad y el género, lo cual redujo el cuerpo y su fuerza física para fines de explotación y dominio directo. La economía cafetalera requería fuerza de trabajo y esta comprendía a niños, adolescentes y jóvenes, sin distingo alguno, salvo la especialización y destreza alcanzada en las etapas joven y adulta. 
La historia del largo siglo XX registra no solo la ausencia de condiciones mínimas de instrucción educativa para la inserción laboral, sino también la ausencia misma de leyes que restringieran el trabajo infantil. Ante esta ausencia, los jóvenes, desde niños y adolescentes, han sido incorporados al trabajo de las fincas cafetaleras, las plantaciones de algodón y otras actividades del sector rural. De igual manera, algunos estudios registran el reclutamiento de jóvenes campesinos para engrosar las filas de las fuerzas militares, cuyo adiestramiento, en algunos casos, involucra una lógica genocida, esto es, de exterminio a los enemigos, aunque sean de origen similar al de ellos, campesinos e indígenas pobres. ${ }^{3}$ Además, quienes formaron parte de los movimientos de la resistencia, adheridos a los comunistas, fueron igualmente jóvenes dispuestos a la defensa de sus mínimos derechos.

La historia registra que la categoría de jóvenes es fundamentalmente de origen urbano, se refiere a estudiantes universitarios y a jóvenes incorporados al mundo laboral. Sin embargo, los jóvenes del mundo rural, dentro de sus reducidas opciones, hicieron suya no solo la movilidad campo-ciudad y la emigración interna, regional e internacional, sino también la resistencia a los poderes instituidos, lo cual hizo posible el estallamiento social que dio lugar a la guerra civil. En efecto, durante este enfrentamiento, las invocaciones funcionales de los jóvenes fueron desplazadas por la denuncia y combate a su activismo político en el seno de la guerrilla. Como rasgo propio del capitalismo, los jóvenes se definen por su origen social, es decir, se definen y se particularizan de acuerdo con las divisiones económicas, sociales y políticas de la sociedad en la que están insertos.

En El Salvador no hubo un joven en abstracto, sino un sujeto real, en concreto, materia y conciencia. Con la guerra civil, cuando la participación activa de este se hizo visible, logran una identidad política definida por el estatus de clase y el marco de posibilidades o limitaciones que el contexto ofrecía. La historia registra, aunque sin mucha precisión, la participación tanto de los jóvenes en la Unión Democrática Nacional (UDN), en 1969, en cuyos antecedentes figuran el auge de la lucha de la Resistencia Nacional (RN) y del Partido Revolucionario de Trabajadores Centroamericanos y sus frentes de masas (FAPU y MLP, respectivamente), como de los jóvenes de familias pudientes y de la élite castrense, quienes portaban movimientos adscritos a su origen. Con todo, la represión militar hizo de la protesta cívica respuestas armadas, las cuales van a ampliar el margen organizativo de miles de jóvenes y su incursión en la guerra civil.

Formalmente concluida la guerra civil con la firma de Los Acuerdos de Paz, en 1992, que hizo de la democracia representativa la panacea para un nuevo orden, en El Salvador ocurrieron acontecimientos y procesos que vuelven a tornarla una "democracia de fachada". La arena de la política perdía su fuerza anticapitalista y fortalecía, con la democracia liberal, una nueva fuerza capitalista. Fueron insuficientes Los Acuerdos de Paz y las buenas intenciones de algunos países latinoamericanos y europeos por 
sentar las bases, con sentido de restauración social, de gobierno y sociedad. En los años de la misma guerra civil, se vivió en la región la crisis económica y el ajuste que impulsaba una nueva fase del desarrollo del capitalismo:

Desde mediados o finales de la década de los ochenta, paralelamente a la negociación de los conflictos armados, se produjo en la región centroamericana una serie de procesos que, con diferencias de matiz y grado, procuraban la inserción de las economías locales en las dinámicas de apertura y globalización (Morales 122).

Paradójicamente, como señala Morales, esta inserción encontró en los saldos de la guerra civil el sustento más formidable para ello. Se refiere a los grandes procesos de movilidad y migración que alterarían la estructura y dinámica de los habitantes de la región. Se calcula que los desplazamientos forzados de personas de sus lugares de origen afectaron a más de dos millones de pobladores: el más importante, el desplazamiento interno, con casi un millón de personas; y el de los desplazados no reconocidos como refugiados, con casi 700 mil. Se indica que "casi un tercio estaba caracterizado por población en edad activa" (Morales 121). En suma, se reconoce que las corrientes migratorias marcan en los años previos y durante la guerra civil "un nuevo momento, un nuevo rumbo y nuevos perfiles".

Indica Morales que los censos de Estados Unidas registran que la migración centroamericana a ese país pasó de 331219 en 1980, a 1.1 millones en 1990 y a 1588 239 en el año 2000. De esta, la inmigración de El Salvador pasó de 94447 personas en 1980 a 465443 en 1990 y a 655165 en 2000. Sin embargo, indica que las estimaciones del Centro Mumford registraron 2681836 personas residentes en Estados Unidos en 2000, de los cuales 1117959 son de El Salvador (Morales 135). La guerra civil derivó en un éxodo hacia Estados Unidos, pero su continuidad creciente después del año 2000 obedece, además de las catástrofes naturales de 1998 y 2001, a los impactos de un modelo económico excluyente. El Programa de las Naciones Unidas para el Desarrollo de 2017, registra que actualmente "alrededor de 2.5 millones de salvadoreños viven en el exterior, la mayor parte de ellos (85 por ciento) en Estados Unidos” (INEDIM, 4 de marzo de 2017).

El fin oficial de la guerra en El Salvador no posibilitó la construcción de una agenda sobre la problemática de sus jóvenes. La restricción de la participación política y la severidad del ajuste económico, propiciaron no solo la continuidad de los flujos migratorios, sino también la incapacidad interna de una estructura institucional básica para enfrentar situaciones de retorno o de deportaciones de su población migrante. Sin embargo, su entrada formal a la democracia liberal, como la expresión política del fin de la guerra civil, se tiñe de una nueva violencia. La dependencia extrema de El Salvador con respecto a Estados Unidos se va a visibilizar en el sector más vulnerable de su población migrantes, los jóvenes, pues son ellos, en la figura del pandillero y la 
pandilla, los nuevos actores de su consustancial racismo, en las que no se pierde la vieja extrapolación, en clave biológica, del "enemigo político" (Cavalleti 258).

La sensibilidad analítica de este proceso sin fin se constata en las numerosas investigaciones de la academia salvadoreña y centroamericana. Dan cuenta de la criminalización y deportación masiva en los tiempos del presidente Bush y después del presidente Clinton, consolidada en el del Violent Gang Task Force, y en subsecuentes políticas migratorias restrictivas. ${ }^{5}$

Las declaraciones del Gobierno estadounidense, sustentadas en cifras y hechos, y el fortalecimiento de sus estrategias punitivas y de securitización, ${ }^{6}$ dan lugar a representaciones y a imágenes que dibujan a jóvenes violentos per se. Se registra, tras los disturbios del año 1992 en Los Ángeles, que 1000 salvadoreños fueron deportados (Booth et al.). Otras fuentes sostienen que, de 1993 a 1999, 60450 nacionales del Triángulo Norte de Centroamérica fueron expulsados. El 32.9 por ciento de estos fueron clasificados como "criminales". De la cifra total de expulsados, los salvadoreños representaron el 35.7 por ciento, es decir, 21580 personas expulsadas; no obstante, estos representaron el 47.5 por ciento de los "criminales" deportados.7

La interpretación política y mediática que el Gobierno estadounidense hizo de estas estadísticas fue suficiente para que los jóvenes expulsados, quienes llegaron a su tierra natal, fueran estigmatizados por las instituciones gubernamentales y por amplios sectores de la misma sociedad civil. Se asumió y se propagó el discurso político y el de los medios de comunicación, según el cual estos jóvenes se apoderaban de territorios y de adeptos locales, sin que mediara, como mínimo, un censo básico sobre sus condiciones concretas de expulsión y de llegada.

Si la guerra civil representó uno de los capítulos más oscuros y sangrientos de El Salvador, la entrada al siglo XXI anunciaba otro capítulo más violento, no solo por su visibilización subjetiva de violencia social, desverticalizada de los poderes políticos y económicos, sino también por la puntualización de los jóvenes, incluso niños y adolescentes, como victimarios en la figura de las pandillas. El impacto mayor es la vulnerabilidad y el riesgo propiciados por la edad, en tanto posibilidad de ser pandillero y la subsecuente generalización de la violencia al conjunto de la sociedad atrapada en una violencia simbólica encarnada en un campo semántico dominado por nociones de "crimen organizado", narcotráfico, pandillas y seguridad, lo cual impone el trastocamiento de sentido del conflicto y su tratamiento.

\section{Los laberintos de las representaciones de la violencia juvenil salvadoreña en el siglo de la globalización}

El andamiaje ontológico y discursivo que sobre la violencia juvenil asume el Gobierno y la sociedad de El Salvador, imbuidos de la prédica del Gobierno estadounidense, primero hacia los inmigrantes expulsados categorizados en las figuras de 
las pandillas y, después, al calificar a todo extranjero de "posible" terrorista, ha propiciado uno de los mayores problemas políticos a la hora de enfrentar, desde el ejercicio cotidiano de gobierno, el control y la regulación de dicha violencia. Los juicios que condenan sin más a los jóvenes se explican porque estos están inscritos en una concepción de subjetividad humana, cuyo aterrizaje en la realidad concreta evidencia una incapacidad de comprensión, tanto por la complejidad de problemáticas que esta condena encierra, como por los intereses de poder en juego.

Las contradicciones discursivas devienen con tan solo preguntarse sobre los sustentos que definen qué se entiende por la "articulación de los jóvenes con la violencia" y quiénes son los jóvenes, además, si todos son violentos. También cuando se pregunta sobre los fines que sostienen los jóvenes pandilleros al ejercer la violencia. Esta última pregunta cuestiona las respuestas de las dos primeras, porque, para las lecturas dominantes, los fines se reducen al gozo instintivo de la violencia, esto es, una violencia en sí misma y, en el extremo, estos están mediados por los vectores de la "violencia negativa" de la globalización (crimen organizado, narcotráfico, trata de personas, corrupción policial, Estados corruptos, entre otros), sin que se llegue a especificar cuál es la violencia que corresponde al segmento definido como jóvenes y cuál la violencia que corresponde a cada uno de los actores de la llamada violencia negativa global.

De entrada, se encuentran las contradicciones de los datos, que, como construcciones de poder, vale preguntarse quién los formula y para quién y para qué se formulan. Desde el amplio campo del derecho internacional público, portador de los derechos humanos, se registran numerosos organismos internacionales adscritos a Naciones Unidas, cuyo cometido es el diagnóstico regional sobre los problemas del desarrollo. En este caso, la violencia en Centroamérica, particularizada a El Salvador y sus jóvenes, los datos de estas son amplios y se complementan con diagnósticos y estudios de organizaciones no gubernamentales (ONG) de países del Norte, los cuales cubren un diagnóstico con cierto margen de fidelidad de hechos y acontecimientos; los datos son también creaciones tanto de organismos e instituciones públicas, como de organismos universitarios y de investigación, de medios de comunicación y de sectores particulares de la sociedad local.

Existe consenso en que la variable para medir el grado de violencia son las tasas de homicidio. Estas colocan a la región Centroamericana, particularmente al Triángulo Norte, con las más altas en el mundo durante los años que van del siglo XXI. De acuerdo con la Oficina de Naciones Unidas contra la Droga y el Delito (UNODC, por sus siglas en inglés) (2017), en el año 2000 los países del Triángulo Norte (El Salvador, Guatemala y Honduras) registraron tasas de homicidios de 60, 26 y 51 por cada 1000000 habitantes; en 2005, las tasas fueron de 62, 42 y 35; y, para el 2010, se registran tasas de 65, 41 y 82.

InSight Crime, por su parte, indica que las tasas de homicidio para cada uno de estos tres países fueron de 103, 19.5 y 56.7 por cada 100000 habitantes. En 2016, la 
misma fuente registra que las tasas de homicidio por cada 100000 habitantes fueron de 81.7, 27.3 y 58. La lectura anual desde esta variable, sometida a escrutinio securitario, político y mediático, pareciera depender del dato y de la funcionalidad de las relaciones entre los órganos de seguridad nacional y las pandillas o entre estas (Véase Escotto, Villalobos, Kinosian, et al. 4, 14).

En torno a este indicador, se registran dos tendencias: el incremento de los homicidios múltiples y el perfil de las víctimas "son de manera creciente hombres jóvenes que viven y trabajan en las zonas rurales y personas que por sus ocupaciones y oficios tienen que trasladarse continuamente de un lugar a otro". Lo confirman las edades de las víctimas, mayormente entre el 40 por ciento son personas entre 18 y 30 años, y el 20 por ciento entre 31 y 40 años. Dos datos más se refieren a los lugares de los homicidios, ocurren, sin excepción, en todos los departamentos y se explica por el crecimiento numérico de las pandillas, estimado en 60000 personas, cifra que hace de El Salvador el país que tiene más miembros de pandillas per cápita (Kinosian et al. 9).

A esta primera fotografía cuantitativa, se le suma otra que devela el alto porcentaje de jóvenes víctimas de homicidio. Un estudio de la OMS, de acuerdo con WHOSIS (World Mortality Databases), indica que las tasas más altas de homicidio juvenil del mundo se registran en El Salvador (92.3), seguido de Colombia, Venezuela, Guatemala y Brasil (citado por Escotto 10) ¿De dónde emerge el discurso político y mediático de los jóvenes como portadores de la violencia? ${ }^{8}$ La respuesta exige haber respondido a las dos preguntas hechas con antelación, referidas al para quién y para qué se formulan.

De manera sintética, se afirma que la producción de diagnósticos y análisis sobre la violencia y sus vínculos con la juventud tienen un objetivo compartido: conocer las distintas vertientes problemáticas del fenómeno en cuestión. No obstante, de acuerdo con la argumentación de Balíbar, este conocer de la violencia y la idealidad que le domina, que es el rehuirla, reducir sus niveles o eliminarla, genera efectos que exigen ser afrontados en clave política. Los actores institucionales locales, en su afán de imponer o restituir el orden, priorizan el dato como directriz del diagnóstico, para legitimar, en su caso, el uso de medios extremadamente violentos; los organismos internacionales y organizaciones no gubernamentales priorizan el dato, pero, bajo una retórica crítica que tiene como marco referencial el modelo de sociedad democracia violentada, argumentan y exigen la pronta restauración de sus instrumentos políticos y normativos.

Las ambivalencias, paradojas y aporías que definen el pensamiento y las prácticas sobre el fenómeno de la violencia, se visibilizan cuando se trata de definir el carácter de víctimas y victimarios de los jóvenes. En su carácter de víctimas, el dato es frío, cuando no invoca la sentencia de que los jóvenes pandilleros se matan entre sí, invoca una irresponsabilidad difusa de la sociedad como un todo. En su carácter de victimarios es visible, desde las figuras de la Mara Salvatrucha (MS13) y Barrio 18, el extenso repertorio de actos y prácticas violentas de las que se les acusa, al grado 
de parecer ser los actores directos de toda la violencia de El Salvador. Las evidencias mediáticas son tan potentes que tienen la capacidad de construir representaciones e imágenes que alteran el entramado intersubjetivo de la sociedad, para clamar medidas militarizadas y emitir consignas como la de "liquidémoslos" (Kinosian et al. 5).

¿Se puede? El Gobierno salvadoreño, con el respaldo de las fuerzas conservadoras, decide emprender el combate directo -guerra-contra las pandillas, al otorgarle a sus fuerzas de seguridad el derecho de matar. Los reveses están a la vista, una violencia incruenta entre fuerzas de seguridad y pandillas, sin visos de alcanzar la promesa de restitución del orden bajo el sustento del derecho constitucional. Los hechos concretos revelan que en las operaciones de las pandillas está involucrada una parte sustancial de la población, además de un vertiginoso reclutamiento de jóvenes. En suma, las pandillas son parte integral de la sociedad salvadoreña. A sus redes:

Pertenecen hasta 600000 personas, en un país con cerca de 6 millones de habitantes, incluyendo a familiares de miembros de las pandillas libres o encarcelados, y quienes viven del dinero que las pandillas obtienen mediante la extorsión de sus víctimas (Kinosian et al. 15).

Sin precisión sobre la magnitud y el carácter del involucramiento de la sociedad local en las operaciones de las pandillas, pero enterado de su importancia, el Gobierno salvadoreño emprende el modelo de "mano dura" contra las pandillas, al situarse en esa zona de transición de la seguridad pública a la seguridad nacional, la cual torna ingobernable lo real de la globalización y sus violencias. ${ }^{9}$ Una guerra civil interna, bajo el credo securitario de la geopolítica estadounidense, está condenada al fracaso; no solo por la inexistencia de las aseveraciones temerarias de EE. UU. Sobre las pandillas -a las que compara con los grandes cárteles-, sino porque, como reitera el periódico El Faro, la cotidianidad de estos las definen como "pandillas de pobres" (Martínez et al.).

Los medios de información y numerosos estudios dan cuenta de un crecimiento exagerado de las fuerzas policiales y militares y de las inversiones en medios de combate para una guerra sin fin, pero cuyo costo merma las finanzas públicas para fines sociales. Lo anterior deviene, irreductiblemente, en el deterioro político y social de la imagen de Estado y Gobierno, ante la expansión de las operaciones de las fuerzas de seguridad, donde "cualquiera puede convertirse en blanco de sus acciones, especialmente varones, sean estos niños o jóvenes" (Kinosian et al. 15).

\section{Los jóvenes "sin lugar". Expulsión, apropiación y vivencia ${ }^{10}$}

En una búsqueda interpretativa sobre la violencia del tiempo global, la cual en el Sur no está desarticulada de esa violencia sistémica y simbólica del siglo XX, se puede proponer la recuperación analítica de la vida cotidiana de y desde los jóvenes, sustentada en la noción de "precariedad extrema" como de "modo de vida" y, en íntima 
articulación a esta, la noción del "no lugar". Sintéticamente, la noción de precariedad y su sentido de "inseguridad", pensada para la sociedad desarrollada de Occidente como nueva forma de regulación y no como condición episódica (Butler; Lorey), se puede pensar como "precariedad extrema", la cual, en la analítica de Goldberg, se refiere a una condición de inseguridad "ordinaria" que trastoca tanto los límites funcionales tradicionalmente adscritos al Estado, a la sociedad y al sujeto, como el campo de las subjetividades y representaciones que le hicieron posible.

El punto de tensión vital que se debe registrar es el que se da entre la amenaza de la disolución o exterminio del sujeto, por parte de la globalización, y la capacidad de respuesta a través de formas de apropiación de sociabilidades y de sentido, emergentes y provisionales. Como acto cognitivo y evaluativo, se trata de un campo de subjetivación y sensibilidad, ${ }^{11}$ cuyos elementos en permanente desequilibrio, desconfiguran y reconfiguran las formas de categorizar a los demás y a uno mismo (Dubar 253, 259).

La noción de "no lugar" evoca a cientos de miles de jóvenes del Sur que tienen tras de sí una experiencia existencial "quebrada con el rayo de la desgracia, cuyo horizonte bifurcado aleja toda posibilidad esperanzadora" (León 17). La vulnerabilidad de los jóvenes y con sentido de continuidad y emergencia las mujeres, los adolescentes y niños, en tanto sujetos de los procesos de movilidad y migración global, obedece no solo a las dimensiones de la edad y del género, y al arrastre de violencias sistémicas y contingentes que traen consigo, sino fundamentalmente al despliegue de estrategias de criminalización y de militarización en países de tránsito y de llegada, que deconstruyen con creciente cinismo las premisas de la desespacialización y desfronterización, en tanto pilares de la libertad del mercado y del individuo, para restituir las tesis schmitianas del carácter político del espacio, y, con esto, la oposición política amigo/ enemigo (Schmitt).

La noción de "no lugar", como la condición global de los jóvenes del Sur, se puede definir como la indeseabilidad de su existir, concretizada en dispositivos que provocan la recurrente expulsión de sus espacios vitales, lo cual priva como fin último no el control y la regulación de antaño, sino la disolución, el exterminio o la muerte (Goldberg; Bauman). No obstante, la noción de "no lugar" entraña su contrario, esto es, espacio de vida, un "no lugar", vivido, o como condición de vida.

Un ejemplo de esta doble dimensión que caracteriza la noción de "no lugar" se ha registrado con jóvenes de la ciudad de San Salvador, cuya experiencia de vida conjuga la paradoja de la expropiación y apropiación de las dimensiones vitales de sus vidas cotidianas u ordinarias, lo cual devela una experiencia de producción de subjetivación y de sustracción que posibilita enfrentar los desafíos de una violencia con muchos rostros, y la tarea imparable de "negociar" el derecho a la vida. Son jóvenes que viven en el país de origen, acaso de algún país cercano; no son "pandilleros" pero de distintas maneras estos están cercanos a su vida diaria. En sus intersticios, entraña la construcción de una política menor (Goldberg 15; Carretero y León 164; Agamben 94). 


\section{La casa, la colonia y la ciudad expropiada}

El espacio como derecho de vida no está garantizado. El espacio íntimo, la casa, la calle, colonia y la escuela "se negocia día a día", priva en el decir, en el contar de los jóvenes, la paradoja de la enajenidad y de lo propio, " $m i$ casa, mi colonia, que no es mi casa, que no es mi colonia.

Vivir en el municipio de Ciudad Delgado, no me parece "peligroso", se pude estar caminando tranquilamente con teléfono en la mano, a menos que uno se adentre hacia un lugar o callejón, donde pueden fregar a uno. Ciudad Delgado tiene fama de ser algo complicado, pero es más en los cantones o lugares de zonas rurales más apartadas del centro; si hay presencia de maras y sí de vez en cuando asesinatos y cosas así, incluso en el centro, pero no tan frecuente como en otros lugares, entonces por lo menos para mi es un lugar tranquilo donde puedo andar caminando y todo (Anónimo, mayo de 2017).

Vivir en Soyapango es un vivir raro. Vivir dentro de la colonia, siento una paz relativa porque uno sabe que el muchacho pandillero es tu amigo, fue tu compañero, jugaste con él, entonces no te va a hacer nada. Hay control de quien es el que vive adentro. El riesgo es de quien no vive en la zona: si es una mujer piensan que puede ser la mujer, la mamá o la tía de un pandillero (del bando contrario). Yo puedo estar también con el celular en la mano y todo, pero ahi adentro, porque si yo salgo de Soyapango -es otra cosa (Anónimo, mayo de 2017).

Vivir en Santa Ana no es tan riesgoso, aqui controla la mara salvatrucha, solo en el centro, o en algunas colonias, hay un pedacito de contrarios. Se crea cierta identidad dentro del mismo barrio porque ya decís: los chavales ahi te pueden hacer algo si te vas a meter al lado contrario (Anónimo, mayo de 2017).

Vivir a cinco minutos de la universidad y cerca está el Hospital Militar, no es un vivir de peligro, hay patrullajes, no hay pandillas, no estoy sujeto al control de ninguna (pandilla). Pero en Lourdes, donde colaboró en un programa de alimentación, es diferente, se siente extraño, por la forma en que lo auscultan a uno, cuando estoy fuera del comedor veo el entorno en que operan las pandillas (los dieciocho revolucionarios). Ofrecen una cierta seguridad, pero tiene un costo, si no pagas no te dan seguridad, está en peligro tu vida. No me ha tocado, ando con el carnet de la universidad por cualquier cosa (Anónimo, mayo de 2017).

Vivir en Apopa en la colonia Valle del Sol, colonia famosa porque ahi fue el paro de transporte declarado por las pandillas, no me da miedo, puedo caminar tranquilo en mi colonia, pero no en otra colonia, la gente que llega y no es de la colonia se las ve difíciles, no hay excepción. 
Con todo, Apopa es un lugar muy violento, la colonia Tikal también lo es y domina la pandilla dieciocho revolucionario, solo hay un puntito en medio de esa gran zona donde vivo que es la zona ciento dos, ahí está la mara... pero de ahí para allá en el centro de Apopan abarcando Ciudad Delgado, casi todos son dieciocho (Anónimo, mayo de 2017).

\section{La vida con las pandillas}

Las narrativas sobre el vivir con las pandillas en la colonia o fuera de esta, compromete la producción de subjetividades que definen las relaciones intersubjetivas en el pequeño espacio social de la colonia o del barrio. La convivencia desde la infancia con jóvenes pandilleros y el riesgo a ser violentado por las otras pandillas fuera del barrio, irrumpe, con un sentido natural, esa figura y ese discurso de malignidad mediática y política.

Ya tiene años lo de las pandillas, y hay cambios que hay que decirlo. Con la evolución de la mara y la pandilla ya no hay tanto robo en el centro de San Salvador, como en los buses que se suben a pedir un dólar o dos dólares por cabeza, pero en el centro ya no es tanto de que van a quitar la cartera, como en la Avenida España, en dos mil tres, todo era peligroso, pero como la mara es la que controla todos los puestos, ellos dan seguridad, nadie se atreve a jalar una cartera, un pantalón de un puesto y salir corriendo porque ya están sentenciados a que los partan en varios pedazos. Hay reglas también, tienen reglas de cuidar a los vendedores. Mi cuñado me dice, que un marero le dice al otro marero: cuídalos a los vendedores que de ellos estamos comiendo... ya no es como antes, esa evolución de las maras que se ha organizado también ha hecho de que ya no haya tanto ratero común y corriente (Anónimo, mayo de 2017).

Los permisos son para todo. Las mismas maras, para asaltar piden permiso, nosotros ya sabemos quiénes son los que no asaltan. Para beber, también piden permiso, no pueden trabajar "tragueados". Si, hasta para robar hay permiso. Hasta nosotros tenemos que pedir permiso, por ejemplo, para usar la marca de los zapatos, estaba prohibido que usáramos el zapato "concha" y el "lacoste imitación, pues", un pandillero te puede dar ese permiso. Han dejado usar marcas que antes no dejaban usar, solo ellos, son sus reglas, "no podía tener zapatos o ropa con marcas que solo eran para ellos, rápido te paraban, aunque te conocieran y te decían ¿vos qué pedo? (Anónimo, mayo de 2017).

Yo tengo que trasladarme entre dos colonias, donde vivo y donde vive mi abuelita, tiene una calle que es la división en la que yo vivo es de la dieciocho, pero ellos protegen a narcotraficantes (que andan cobrando). Del otro lado donde vive mi abuela está la pandilla contraria. Yo tenía la manía de salir corriendo con unos "nike" (negros con verde). Un día me paran y me dicen que por qué iba todos los días, en ese año sacaron a muchos mareros de la cárcel y venían 
tras de todo. Me dijeron ¿Y vos porqué andas esos colores? (eran los colores de la dieciocho), me sentaron en una esquina, me advirtieron completamente que no volviera aparecer por ahi, porque si no, no la iba a contar". Me quitaron los zapatos, el teléfono, vieron qué tipo de música escucho, porque hay artistas que solo es para una pandilla y otros son para otra pandilla. Me salvé porque uno de ellos fue a preguntar al lado en la colonia de mi abuelita si yo era de ahi, por eso me dejaron ir. Hasta después de año y medio me mandaron a decir con un primo que los tres que me habian agarrado ya los habían echado (Anónimo, mayo de 2017).

Pasa igual con los códigos de la vestimenta, con los estampados, hay que saber utilizarlos, hasta los cortes de pelo. Para matar también (se pide permiso). Me dicen: tienes que ver, qué día hay más muertos, ese día, es el día que hay más permisos. Por ejemplo, si un pandillero le cae mal a " $x$ " del sector, no puede nada más dispararle y decir ya me la desquité, sino que también tiene que pedir permiso al jefe, y él le da el pase (Anónimo, mayo de 2017).

También hay códigos cuando uno trae carro y entra a la colonia, cuando yo entro a mi colonia, en la noche, tengo que entrar con luces bajas, o si no tengo que dar como dos lamparazos para poder entrar y entonces ya saben que uno es de ahí (Anónimo, mayo de 2017).

\section{¿Y el Estado? La vida cotidiana "también entre militares y policías"}

Los procesos de estimulación política y mediática que el Gobierno y sectores empresariales construyen en torno a la figura violenta de los pandilleros y la lucha por su exterminio, en tanto amenazan la estabilidad de la cultura política hegemónica, tienen poca recepción entre los jóvenes "no pandilleros", porque son victimizados y perseguidos por el Estado sin distinción.

El Gobierno ha sacado más soldados, ha sacado batallones, y mi cuñado dice que eso es lo que da más miedo, y es cierto. Hay más inseguridad porque quienes no nos metemos en nada, huimos de los soldados, y de las maras, quedamos siempre en medio, porque los soldados en la colonia empiezan a "moretear" (golpear) a quien sea, no les importa que sean o no maras, para los soldados quienes viven en Valle Sol y las colonias marcadas están relacionados.

Es un hecho, aunque uno no tenga nada que ver, amenazan y moretean, es más, a veces hay más irrespeto de parte de ellos que de los propios pandilleros, porque asumen de que, porque ella sea mujer es la mujer de un pandillero. 
Siento inseguridad cuando llegan los soldados, como yo soy de ahí, de la colonia, me conocen, pero los soldados no, entonces esa esa es la inseguridad que uno va sintiendo (Anónimo, mayo de 2017).

El peligro es también estar en grupo, te pueden llevar, es un temor de siempre en la colonia. A veces tomando una gaseosa y de repente pasan, se les tiene más temor a los policías que a los propios soldados. Pero también a los soldados, hace dos años recuerdo, salieron los de "boina roja", esos vienen y no te van a dejar, te dan duro. Ellos son de las Fuerzas especiales del Ejército (Anónimo, mayo de 2017).

Los datos que tengo sobre la policía y los militares coinciden con la violencia indiscriminada de antes, es decir que saben en tal cantón hay guerrilleros, llegan y "arrasan" con el cantón, es lo mismo que con las colonias, si están marcadas llegan y "arrasan" con las colonias, es lo mismo de los años setenta y ochenta.

En noviembre del año pasado, estaba en mi casa y oí que estaban pujando los chamacos, los soldados los estaban fregando, tenían a todos de "pichón", no eran pandilleros han crecido conmigo ahi, los fregaron solo porque estaban sin camisa y los miran como los peores. Hubo coraje, hasta yo entré en cólera, y les dije que estos pichones son de la colonia, me dijeron vos cállate y me pegaron... para ellos todo mundo es de la mara y la pandilla, la pandilla de los dieciocho y la mara salvatrucha (Anónimo, mayo de 2017).

El gobierno no sabe qué hacer. Cuando salieron los soldados, los pandilleros, de los sectores de allá de Santa Ana se escondieron, pero como hubo crítica que de los militares están para defender la soberanía nacional, no la seguridad pública, volvieron al cuartel, pero entraron nuevamente las pandillas, y volvimos a la misma situación.

La estrategia de "mano dura" y "súper mano dura" fue también un fracaso, el problema había salido de las manos del gobierno, desde los noventa dejó que la delincuencia se le fuera de las manos.

El presidente Cerén no ha podido tampoco. Es un problema viejo, incluso yo siento que es parte de la cultura del salvadoreño, la gente no demanda y muchos casos quedan impunes, en el aire, el gobierno es incapaz de llegar a todos los sectores. Demandas, pero llegas a tu colonia y te topas con un pandillero, y si los demandaste alguien te va a matar. En los últimos tres o cuatro años, hay más delincuencia, se han disparado las muertes, ya tienes más confianza, tienen redes 
estructuradas, ya no son aquellos niños que han venido de Estados Unidos, ahora los de las pandillas es algo más serio y el gobierno no ha podido hacer nada.

Uno ya no tiene confianza con el gobierno porque está involucrado hasta ahí el crimen organizado. A mí me tocó vivir una situación de afectación, pusimos la denuncia y a los treinta días me habló un inspector, pero después un conocido me dijo que este pertenecía también al bando de delincuentes, que yo no procediera, porque me podían matar a mí o a mi familia. Es un miedo que todos tenemos con el gobierno, a lo mejor arriba hay buenas intenciones, pero toda la estructura que está abajo está completamente arruinada (Anónimo, mayo de 2017).

Yo pienso que hay corrupción, una corrupción bastante seria, uno puede hacer una denuncia en la comisaría que está en la colonia, pero ahí hay gente que son allegados a los pandilleros. No sé si los policías saben también que fui a denunciar, pero hay ciertas alianzas que todavía están en el poder anterior de ARENA (Alianza Republicana Nacionalista).

Los partidos y los políticos, en los procesos electorales arman sus teatros, hasta establecen relaciones con las pandillas para que vayan a votar, por ellos por supuesto. Lo hacen todos los partidos, ninguno se salva, así sea el más fuerte. Con Funes, presidente de izquierda el país llegó a ser el país más violento del mundo (Anónimo, mayo de 2017).

Hasta uno de "arriba" dijo que las maras hagan política porque ejercen la violencia. Eso ya dice mucho de la política en El Salvador.

No se están haciendo cambios en donde está el origen estructural del problema. Poner canchas para que los jóvenes vayan a jugar en vez de estar de delincuentes, es como poner curitas sobre la piel donde hay una herida grande (Anónimo, mayo de 2017).

\section{Ser mujer joven en El Salvador:}

Si voy al centro de la ciudad, yo espero el bus de mi colonia, no me subo a otro. Igual, cuando voy para mi casa, en Soyapango, tomo el bus de mi colonia, aunque no vaya todavía a mi casa, porque de alguna manera los motoristas, los promotores, ya tienen identificados a los pasajeros, entonces yo me siento más segura. Hay otros "buses" pero no los tomo. Ellos cuidan las colonias. Vivo en Soyapango desde que tenía 4 o 5 años, eso que ocurre con los buses lo empecé a vivir cuando tuve que ir al colegio, recuerdo que mi mamá le pagaba a una señora que me llevaba y me llegaba a traer al colegio. Empecé a ir sola hasta los 14 años. 
Yo procuro llegar temprano a mi casa, lo más tarde es a las 7, si no tendría que quedarme con alguna conocida. Después de las 7 ya no puedo irme a mi casa. Me ha tocado ver casos, nadie defiende, se siente uno impotente. Hasta las 9 de la noche pasan los buses de dos rutas. A veces tomo el taxi que es de un vecino nuestro.

Para mi es difícil organizar mi vida, mi exnovio era de Lourdes, de inmediato hay asedio, los vecinos quieren saber de él, y tenemos que ponernos de acuerdo qué decir ante tanta pregunta. Le decían que era inspector por su complexión y su vestimenta, pero estudiaba medicina. Yo misma les hable a los muchachos ("pandilleros"). No es fácil tener un novio que sea de otro barrio, o que sea pandillero. Ellos te ponen barreras, dicen quién entra y quién sale. Ahora, siento que tendría que andar con alguno de ellos.

Con mi amiga, aplicamos inyecciones en la colonia, a las muchachas que van a Estados Unidos y ya sabe, son anticonceptivos, muchas son vírgenes, hasta niñas de 13 años. Pero también a las parejas de los pandilleros les inyectamos anticonceptivos. Hago favores $y$, de hecho, el respeto de ellos es hacia mí, hacia mi hermano y mi mamá. Mi hermano es profesor y siento el respeto de ellos hacia nosotros.

En mi colonia está la dieciocho. Si he pensado irme. Sin querer uno se va comprometiendo, sobre todos los niños y eso si da tristeza porque les hacen daño, hacen los favores que ellos piden, pero cuando dicen stop, se tienen que ir. A veces toda la familia se va, a veces solo ellos.

Mi mamá me ha dicho que si llegara a tener la fortuna de irme que me vaya, me dice que ella ya vivió, que me vaya. Es difícil también irse. Con mi hermano y su esposa, pensamos irnos, como son cristianos, cuidan a la familia. Ya no se puede vivir aqui, es la otra cosa, sería en otro país. Pero no sé (Anónimo, mayo de 2017).

\section{La violencia en El Salvador y el magma de la violencia global}

Las narrativas del puñado de jóvenes entrevistados en la ciudad de San Salvador, sumado a las de jóvenes que osan transitar el territorio mexicano para llegar a los Estados Unidos, y jóvenes, hombres y mujeres, que intentan por vías legales, salir a trabajar o estudiar a otros países, particularmente México, encierran el sentido de su disolución y su forzamiento a vivir en condiciones de precariedad extrema, y a un vivir en vilo, como "modo de vida". En las palabras y percepciones, tan simples y sinceras, sobre las dificultades para existir, se registra ausencia de poder, o de querer tener poder para socavar el miedo, y sus ambigüedades, que se va internalizando en el modo de ser en sí mismo. ${ }^{12}$ 
Sin embargo, “iNo podemos quedarnos de brazos cruzados!” es una expresión que se despliega en una multiplicidad de acciones y prácticas que hacen posible que la vida de los jóvenes en El Salvador siga su curso o este sea irrumpido por decisiones temerarias, como asistir a una "discoteca, o emprender el "vuelo incierto" hacia lugares desconocidos o imaginados; los que se quedan, reconocen y saben de los límites y de las posibilidades para adentrarse en un sistema dislocado, que se pierde a sí mismo, como si intuyeran que la "desformalización del Estado" es también, como señala Barcellona (35), "la deformación de la ley-norma".

Este conversatorio con jóvenes estudiantes, que muestra el rostro más blando de la violencia en El Salvador, permite establecer una reflexión sobre los significados de la crisis funcional tradicionalmente adscritas a las figuras del Estado, la sociedad y el sujeto. La primera sugiere la idea de que desafección de los jóvenes a las figuras del Estado y del Gobierno está ampliamente legitimada: para ambas figuras, los "jóvenes" no existen en su positividad, en respuesta, para estos, ambas figuras tampoco existen, salvo para "joderlos". La primera ley sobre juventud se creó en 2011 y se aprobó en 2013, casi dos décadas después de las primeras deportaciones de los jóvenes definidos "pandilleros" por las autoridades migratorias y de seguridad de Estados Unidos. No obstante, sin dejar de reconocer su importancia devenida en políticas públicas sectoriales, para los jóvenes no es ninguna herramienta que les permita solventar sus problemas concretos más básicos, como formalmente sostienen. ${ }^{13}$

La segunda, la lectura de los jóvenes sobre su sociedad, es una lectura fragmentada, pero en oposición a la lectura del Estado. El ejemplo más fiel de ello es la percepción sobre el mundo de las pandillas en su entorno inmediato, en abierto contraste con la figura del militar o del político. El modo de significar a las pandillas que es una violencia simbólica y discursiva por parte del poder institucional y mediático no es convincente ni creíble para los jóvenes no pandilleros. La tercera reflexión, es sobre el modo de vida que construyen. Asombra ese pragmatismo, en el que, si bien media el sentido de vulnerabilidad y riesgo, aprenden el significado de vivir en la colonia, en el barrio y en la ciudad y desarrollan dispositivos de negociación y dislocación para desestructurar lo dado, sean estas las reglas de las pandillas o de las autoridades portadoras de inseguridad.

Sobre lo que se sabe y se dice del fenómeno de las pandillas, abruma y pesa su adjetivación "juveniles", que tiene detrás toda una carga de acusaciones que pareciera definir toda la violencia de un país, negándose la fuerza de esa violencia de la globalización "negativa", para sostener el estigma de ser, como todo el Sur, portador de una "cultura de violencia" -el comunista ayer, el pandillero hoy-. Lo nuevo, cabe decirlo, no solo son las representaciones y montajes mediáticos, que deshistorizan y particularizan la violencia, sino también la horizontalidad de todo antagonismo y conflicto, que posibilita situar la violencia en el terreno de lo social, afianzando con ello el llamado "Estado policial" y sus dispositivos securitarios. 
Se ha registrado estudios que reconstruyen la historicidad del pandillerismo salvadoreño, y centroamericano, cuyo origen en el país receptor fue la diseminación una violencia de exclusión y racismo, afianzada en "redes imaginarias del poder" que hacen de los otros los enemigos de la normalidad democrática (Bartra 13). El retorno a la tierra de origen no significó el trastocamiento del estigma que justificó su deportación; al contrario, este se adosó con los mismos vectores del discurso mediático y político que legitimó la expulsión y, con ello, el modo de significar a las pandillas. Los reveses han sido inevitables: el gobierno estadounidense deporta, expulsa, pero el gobierno salvadoreño no puede repetir la misma acción, son nacionales suyos y debe gobernarlos con los sustentos del Estado Constitucional de Derecho (Cruz, Rosen, Anaya, Vorobyeva; Meléndez y Bergmann; Rocha). Deformar los hechos no es una cuestión menor, el mismo Banco Mundial registre que en la región centroamericana el obstáculo más importante son los datos reales, la falta de estadísticas confiables, aunque estos, en manos del poder sirvan solo para sostener, como indica Han la sentencia de que "esto es así y punto".

Este modo de significar tramposamente la violencia de los jóvenes, particularmente los adscritos a las pandillas, tiene detrás de sí, la tensión entre una democracia política y social prometida en los Acuerdos de Paz de 1992,14 y una democracia liberal representativa, la cual se atribuye ser el "modelo de civilización", pero que los excluye con un sentido deliberado, en tanto el "vinculo orgánico" entre desigualdad estructural y radical, y democracia, es "la regla del consenso" (Badiou 37). Regla, que como indica Maresca (87), se traduce, en el corto plazo, en un proceso de "recolonización", y a largo plazo, en una estrategia global de "gobierno de la economía mundializada", "antagónica a los de un gobierno público de la economía". En su despliegue esta regla, bajo el nodo de la categoría de "expulsión", que para Sassen (248) proyecta condiciones planetarias, ${ }^{15}$ se traduce en la destrucción misma de los Estados y de las sociedades periféricas. ${ }^{16}$ Paradójicamente, los Estados locales no solo legitiman y alientan el poder tecnocrático en aras de los fines de competitividad global, sino también, con sentido imperativo, delegan porciones importantes de soberanía a organismos supranacionales, incluyendo el de la seguridad nacional con impactos violatorios en los derechos humanos y fundamentales de su población (Maresca 94).

\section{Dos reflexiones conclusivas}

Pensar la violencia del siglo XXI en los grupos etarios más vulnerables, en ellos los jóvenes, es un desafío cuyo éxito está de antemano negado. Priva en su lectura hegemónica un modo de significarla en la que está ausente la misma posibilidad de construir instituciones políticas y legales con el sentido de oposición a la violencia y el sentido de muerte que entraña. La globalización, en tanto "agenda hegemónica" sin cobertura legal, induce a imaginar y vivir la violencia, y las violencias que engendra, 
con un sentido de inevitabilidad, pues tiene de suyo acontecimientos productores de inhumanidad que, si bien superan las catástrofes del siglo XX, abrevan del mismo sustrato de la modernización. La violencia es así, inextinguible, aunque cambie de forma, y pretenda hoy tornarse anónima.

Las pandillas juveniles existen, junto con estas se institucionalizan las prácticas delictivas y se carteliza el mismo mundo cotidiano, configurando el qué se puede hacer y el qué no hacer, incluyendo la prohibición o no de una estética corporal llevada a sus límites tras el borramiento de lo instituido (INCIDE). La cultura de la muerte, o más bien el instinto por la existencia vital, que evoca esa violencia de la exclusión es una construcción de la que son responsables todos los actores de la sociedad y ninguno se libra de sus efectos, menos alcanzar la paz tras decretar su inevitabilidad. ¿Qué son los jóvenes para la sociedad y las instituciones salvadoreñas? Es una pregunta que todavía espera su respuesta, la esperan los jóvenes, los adolescentes y los niños, quienes pasan, solos o acompañados, a engrosar la lista de los solicitantes de asilo (ACNUR). En El Salvador, o en cualquier otro país del sur, los jóvenes constituyen la clase marginal del mundo globalizado, una categoría liminar extrema que en palabras de Bauman:

Muestra el horrendo páramo adonde conduce el territorio de la exclusión una vez que se ha ingresado en él: un páramo más allá del cual solo puede haber un vacío, un agujero negro y sin fondo. La clase marginal es el vivo retrato de la nada a la cual un ser humano puede descender, caer o ser empujado; y el infortunio que sufre la clase marginal parece irreversible e irreparable más allá de toda esperanza, hasta un punto sin retorno: una vez alli, no hay camino de regreso, porque no hay retorno desde el Hades; una sola mirada nos enviará otra vez a esa oscuridad intangible, como aprendieron Orfeo y Eurídice de la peor manera: trágica (Bauman 206).

Cabe preguntarse si esta clase marginal suspendida "en un vacío espacial en el que el tiempo se ha detenido", que no "están ni instalados ni desplazados", que no son ni sedentarios ni nómadas, son realmente los victimarios del mundo de las libertades de la globalización.

\section{Notas}

$1 \quad$ Al igual que Hopenhayn y Morán (2007), se opta por el genérico masculino para hacer más fluido el texto, a sabiendas que nos referimos a jóvenes de ambos sexos.

Ya en 1983, el artículo 85 de la Constitución Política establece que los partidos políticos eran el "único instrumento para el ejercicio de la representación del pueblo dentro del gobierno". Reconoce, también, un sistema político pluralista cuya expresión son los partidos políticos (Artiga 137).

3 Sin ser un estudio preciso sobre la inserción de los jóvenes en las fuerzas militares, el trabajo de Manolo Vela sobre los pelotones de la muerte en el caso de Guatemala indaga el origen campesino e indígenas de miles jóvenes que pasaron a formar parte de las fuerzas militares 
e incluso de los batallones de la muerte bajo un adiestramiento sustentado en la lógica del genocidio.

Previo a la iniciativa Safe Streets Violent Crime, enfocada en pandillas violentas, en 1986, indica Rocha, al ser presidente Reagan, se emite la Immigration Reform and Control Act (IRCA), como una estrategia para recuperar el control de las fronteras. Crecen las deportaciones y se imponen sanciones a los empleadores que contrataran ciudadanos que carecieran de una autorización federal para trabajar. Años después, la Ley de 1994 autorizaba al fiscal general a obviar los procedimientos regulares de deportación en el caso de delincuentes que no fueran residentes legales y que fueran inelegibles para un auxilio especial en caso de deportación. El sistema limitó con dureza la revisión judicial. Se creó un centro especial para localizar a no ciudadanos que hubieran cometido delitos. El sistema de deportaciones operó contra la delincuencia extranjera con un bajo costo político.

En 1996 se aprobó la ley antiterrorista y de pena de muerte efectiva, y la ley de responsabilidad inmigrante y de reforma de la inmigración ilegal. Ambas devienen en la normalización de discrecionalidad de las deportaciones, que como indica Rocha, "cambiaron las bases de la exclusión y la deportación, expandieron retroactivamente los delitos que ameritan deportación, estipularon mandatos de detención para diferentes clases de no ciudadanos, diseñaron procedimientos expeditos de deportación para ciertos tipos de casos, eliminaron la revisión judicial para ciertos tipos de órdenes de deportación, autorizaron un reforzamiento jurídico de la participación estatal y local en los procesos de deportación, y crearon un nuevo procedimiento aerodinámico de repatriación -permitiendo el uso de evidencia confidencial- para los no ciudadanos acusados de actividad terrorista".

En 1996 se aprobó la ley antiterrorista y de pena de muerte efectiva, y la ley de responsabilidad inmigrante y de reforma de la inmigración ilegal. Ambas devienen en la normalización de discrecionalidad de las deportaciones, "cambiaron las bases de la exclusión y la deportación, expandieron retroactivamente los delitos que ameritan deportación, estipularon mandatos de detención para diferentes clases de no ciudadanos, diseñaron procedimientos expeditos de deportación para ciertos tipos de casos, eliminaron la revisión judicial para ciertos tipos de órdenes de deportación, autorizaron un reforzamiento jurídico de la participación estatal y local en los procesos de deportación, y crearon un nuevo procedimiento aerodinámico de repatriación -permitiendo el uso de evidencia confidencial- para los no ciudadanos acusados de actividad terrorista" (Rocha s. p.).

$7 \quad$ Los datos para 1993 provienen del Anuario Estadístico del Servicio de Inmigración y Naturalización de los Estados Unidos. 1999 Statistical Yearbook of the Immigration and Naturalization Service, U. S. Department of Justice, Immigration and Naturalization Service, marzo, 2002, Tabla 63, 221-225.

El Banco Mundial, que registra más de 900 maras que operan en Centroamérica, con un estimado de 79 mil miembros, indica que "hay indicios de que éstos son responsables solamente de una parte mínima de la violencia (diversas fuentes sugieren que quizás el 15 por ciento de los homicidios se relacionan con las maras). Además, resulta muy escasa la información confiable que se relaciona con el papel de las maras juveniles en el comercio de narcóticos".

9 Someramente, Kinosian et al. (2016) destacan: batallones antimaras del Grupo de Reacción Policial; el despliegue de miles de soldados y oficiales de policías en las calles; grupos de élite como Los Halcones, las Fuerzas Especiales de Reacción, el Comando Hacha, del Grupo de Operaciones Especiales de las Fuerzas Armadas de El Salvador; el Comando Zeus, fuerza 
militar compuesta por 2821 miembros divididos en nueve comandos especiales desplegados en 42 de las municipalidades más violentas del país para patrullar junto con la policía; el Comando Águila, con 2000 efectivos en 1063 escuelas; los comandos "Sumpul” y "San Carlos", y "Trueno", la fuerza especial de respuesta rápida del Ejército salvadoreño.

10 Este apartado es producto de un conversatorio con estudiantes de San Salvador realizado en junio de 2007. Omitimos nombres y lugar del encuentro.

11 “El ámbito de lo sensible no supone meras reacciones fisiológicas al entorno o, en otras palabras, el cuerpo no reacciona ciegamente al ambiente, siempre existe una carga de sentido: sentir es desde ya darle significado al mundo" (Sabido 39).

El miedo, deviene "en algo así como un mandato natural interior, un saber reaccionar, un modo de instalarse ante el mundo, un modo de percibirlo; una costumbre y hábito mental que atraviesa el cuerpo, las estructuras emocionales, cognitivas y simbólicas comprometidas en los intercambios y relaciones sociales. En suma, el miedo se constituye como una estructura ontológica que alimenta un modo cultural de experimentar y hacer la vida y el mundo" (León 105).

Se trata de la Ley General de Juventud creada en 2011, cuyo organismo rector de las políticas para la juventud, es el Instituto Nacional de la Juventud. "Establece que la Política Nacional de Juventud brindará las directrices sobre programas, proyecto y acciones a ejecutar para asegurar el cumplimiento de los derechos y deberes de los jóvenes". Las políticas sectoriales a ser ejecutadas contemplan: promoción a la participación juvenil; prevención de la violencia y garantía de la seguridad; derechos a la educación; promoción del empleo juvenil; protección de la salud integral; inclusión social, ambiental y cultural; y promoción de la recreación y el tiempo libre (Escotto 17, 20).

14 Referida al Estado democrático moderno, cuyo mínimo es la protección de sus súbditos de la incertidumbre y la vulnerabilidad, incluyendo las generadas por las fuerzas del mercado. Basa su legitimidad en "la promesa de mitigar el margen de la vulnerabilidad y la fragilidad ya existentes que caracterizan la condición de sus ciudadanos" (Bauman 75).

Las expulsiones que la autora las traduce como "dinámicas -sistémicas- que expulsan gente de la economía y la sociedad, en el Sur global, tienen su expresión en el "neoestractivismo", esto es, la depredación de los bienes ambientales globales (tierra, agua y aire) y su creciente mercantilización.

“Porque en la guerra en curso desde el principio se optó abiertamente por dejar bien claro que lo que se ha dado en llamar "la agenda hegemónica" se llevaría a la práctica con o sin cobertura legal" (Sassen 88).

\section{Bibliografía}

ACNUR. Directrices de elegibilidad para la evaluación de las necesidades de protección internacional de los solicitantes de asilo procedentes de El Salvador, 2016. Recuperado de http://www. refworld.org/cgi-bin/texis/vtx/rwmain/opendocpdf.pdf?reldoc=y\&docid=57c8289d4 Agamben, Giorgio. La comunidad que viene. España: Pre-Textos, 2006.

Alvarenga, Patricia. Cultura y ética de la violencia. El Salvador 1880-1932. El Salvador: CONACULTURA/Biblioteca de Historia Salvadoreña, 2006.

Badiou, Alain. De un desastre oscuro. Sobre el fin de la vedad del Estado. Argentina: Amorrortu, 2016. 
Balibar, Etienne. Violencias, identidades y civilidad. Para una cultura politica global. España: Gedisa, 2005. Banco Mundial. Crimen y violencia en Centroamérica. Un desafí para el desarrollo. Washingtong D.C.: Departamento de Desarrollo Sostenible y Reducción de la Pobreza y Gestión Económica, Región de América Latina y el Caribe, 2011.

Barcellona, Pietro. "La teoría de sistemas y el paradigma de la sociedad moderna". Mutaciones de Leviatán. Legitimación de los nuevos modelos penales. Coord. Guillermo Portilla Contreras. España: Universidad Internacional de Andalucía/Akal, 2005. 11-85.

Bartra, Roger. Territorios del terror y la otredad. México: Fondo de Cultura Económica, 2013.

Bauman, Zygmunt. Vidas desperdiciadas. La modernidad y sus parias. España: Paidós, 2005.

Bauman, Zygmunt. Daños colaterales. Desigualdades sociales en la era global. México, 2011.

Booth, John A., Chrisine J. Wade, Thomas W. Walker. Understanding Central America: Global forces, Rebellion, and Change, Boulder. New York, Westview Press, 2014.

Butler, Judith. Vida precaria. El poder del duelo y la violencia. Argentina: Paidós, 2009.

Cardenal, Rodolfo. Manual de historia de Centroamérica. San Salvador: Universidad Centroamericana, José Simeón Cañas, 1989.

Cruz, Manuel. "Juventud, ¿divino tesoro? Una generación vista desde fuera". Jóvenes y adultos. El difícil vínculo social. Coords. Roberto Bergali e Iñaqui Ribera Beiras. España: OSPDH/Anthropos/Universitat de Barcelona, 2007. 28-42.

Cruz, José Miguel, Jonathan D. Rosen, Luis E. Anaya y Yulia Voroyeva. La nueva cara de las pandillas en El Salvador. EE. UU.: Florida International University, 2017. https://lacc.fiu. edu/research/la-nueva-cara-de-las-pandillas_reporte-final_esp.pdf

Dubar, Claude. La crisis de las identidades. La interpretación de una mutación. España: Bellaterra, 2002.

Escoto Quesada, Teresita. Políticas y prácticas de prevención de la violencia que afecta a la juventud en Centroamérica. Análisis comparativo. Santiago de Chile: Naciones Unidas, CEPAL, 2015.

Flores Pinel, Fernando. El Estado de seguridad nacional. El Salvador, un fenómeno de crisis hegemónica. El Colegio de México-Centro de Estudios Internacionales. Centroamérica en crisis. México: El Colegio de México, 1980. 55-80.

Granados, Chaverri, Carlos. "Geopolítica en Centroamérica”. Cuadernos Políticos, 46 (1986): 74-89.

Goldbger, David Theo (2012). Epistemología del desengaño. Tipologías de lo extra-ordinario. Estética y violencia: necropolítica, militarización y vidas lloradas. Helena Chávez Mac Gregor. México: MUAC/UNAM. 15-30.

Han Byung-chul. La expulsión de lo distinto. España: Herder, 2016.

Hopenhay, Martín y Luz María Morán (Coord.). Inclusión y ciudadanía: perspectivas de la juventud en Iberoamérica. España: Agencia Española de Cooperación Internacional para el Desarrollo, Fundación Carolina, 2007.

INCIDE. El Salvador: nuevo patrón de violencia, afectación territorial y respuestas de las comunidades. 2010-2015. El Salvador: Incide/Open Society Foundations, 2016.

InSight Crime. Balance sobre homicidios en Latinoamérica, 2015. Recuperado de http:// es.inSightcrime.org/análisis/balance-inSight-crime-homicidios-latinoamerica-2015

InSight Crime. Balance sobre homicidios en Latinoamérica, 2016. Recuperado de http:// es.inSightcrime.org/análisis/balance-inSight-crime-homicidios-latinoamerica-2015

Kerr N., Derek. "La edad de oro del café en El Salvador 1883-1885”. Mesoamérica, 3 (1982): 1-25. 
Kinosian, Sara, Angelika Albaladejo, Lisa Haugaard. La violencia en El Salvador: no hay una solución sencilla. Washington, D. C.: Center for Internacional Policy, Latin America Working Group Education Fund, 2016.

León, Emma. "La templanza y el silencio discriminante". Virtudes y sentimientos sociales para enfrentar el desconsuelo. León, Emma. Madrid: UNAM-Sequitur, 2012. 17-43.

Lory, Isabell. Estado de inseguridad. Gobernar la precariedad. España: Traficante de sueños, 2016.

Martínez, Óscar, Efren Lemun y Deborah Sontang. "La magia de los pobres que desangra a El Salvador". El Faro. 21 de noviembre de 2016. Recuperado de https://www.nytimes. com/es/2016/11/21/la-mafia-de-pobres-que-desangra-el-salvador/

Maresca, Mariano. "Antes de Leviatán. Las formas políticas y la vida social, en la crisis del imperio de la ley". Mutaciones de Leviatán. Legitimación de los nuevos modelos penales. España: Universidad Internacional de Andalucía/Akal, 2005. 87-118.

Mbembe, Achille. Necropolítica. España: Melusina, 2011.

Meléndez, Oscar y Adrián Bergmann. Violencia en tiempos de paz: conflictividad y criminalización en El Salvador. El Salvador: Secretaría de Cultura de la Presidencia, 2015.

Montes Mozo, S. y García Vásquez, J. J. El Salvador 1987: Salvadoreños refugiados en los Estados Unidos. San Salvador: Instituto de Investigaciones, Universidad Centromericana, 1987.

Morales, Abelardo. La diáspora de la posguerra. Regionalismo de los migrantes y dinámicas territoriales en América Central. San José: FLACSO-Costa Rica, 2007.

Programa de las Naciones Unidas para el Desarrollo. Informe sobre el Desarrollo Humano 2005: Una mirada al nuevo nosotros, el impacto de las migraciones. San Salvador, 2006.

Restrepo, C. La población salvadoreña en Estados Unidos. San Salvador: Serie de investigación. San Salvador: FUSADES, 2004.

Rocha, José Luis. Deportaciones en EU: El lado sombrío del "país de inmigrantes". Envío, 326 (2009). Recuperado de http://www.envio.org.ni/articulo/3993

Sabido, Olga. "El extraño". Los rostros del Otro. Reconocimiento, invención y borramiento de la alteridad. Ed. Emma León. México: Anthropos, CRIM/UNAM, 2009. 25-57.

Sassen, Saskia. Expulsiones. Brutalidad y complejidad en la economía global. España: Katz Editores, 2015.

Schmitt, Carl.Teología Política. Epílogo de José Luis Villacañas, España, Trotta, 2009.

Torres-Rivas Edelberto. La piel de Centroamérica. (Una visión epidérmica de setenta y cinco años de su historia. San José: FLACSO-Costa Rica, 2007.

Trucco, Daniela, Heidi Ullmann, eds. Juventud: Realidades y retos para un desarrollo con igualdad. Chile: Naciones Unidas, CEPAL, 2015.

UNODC. Delincuencia organizada transnacional en Centroamérica y el Caribe: Una evaluación de las posibles amenazas. Viena, 2012. https://www.unodc.org/documents/data-and-analysis/ Studies/TOC_Central_America_and_the_Caribbean_spanish.pdf

Urteaga, Maritza. La construcción juvenil de la realidad. Jóvenes mexicanos contemporáneos. México: Universidad Autónoma Metropolitana, Juan Pablos Editor, 2011.

U. S. Department of Justice. Immigration and Naturalization Service. 1999. Statistical Yearbook of the Immigration and Naturalization Service, 2002. Recuperado de https://www.dhs. gov/sites/default/files/publications/Yearbook_Immigration_Statistics_1999.pdf

Vela Castañeda, E. Manolo. Los pelotones de la muerte. La construcción de los perpetradores del genocidio guatemalteco. México: El Colegio de México, 2014.

Villalobos, Hazel. Tasas de homicidio en Centroamérica del 2006 al 2016: Balance de una década. San Salvador: FUNPADEM, 2017. Recuperado de https://pensandodesdecentroamerica. 
wordpress.com/2017/01/19/tasas-de-homicidios-en-centroamerica-del-2006-al2016-balance-de-una-decada/

Zong, Jie y Batalova, Jeanne. "Central American Immigrants in the United States". Migration Information Source (2 de septiembre de 2015). Recuperado de http://www.migrationpolicy.org/article/central-american-immigrants-united-states-3

María del Carmen García Aguilar. Mexicana. Doctora en Ciencias Sociales por la Universidad Autónoma Metropolitana, México. Miembro del Sistema Nacional de Investigadores nivel II. Investigadora y docente del Centro de Estudios Superiores de México y Centroamérica de la Universidad de Ciencias y Artes de Chiapas, México. Temas de investigación: relaciones de poder y cultura política.

Contacto: mcgarcia2005@yahoo.com.mx

ORCID: 0000-0002-1647-7984

Iván Francisco Porraz Gómez. Mexicano. Doctor en ciencias sociales y humanísticas por el CESMECA-UNICACH, México. Investigador asociado de El Colegio de la Frontera Sur (ECOSUR), Unidad Tapachula, en el Grupo Académico de Estudios de Migración y Proceso Transfronterizos del Departamento de Sociedad y Cultura. Miembro del Sistema Nacional de Investigadores. Temas de investigación: jóvenes migrantes, violencia en el sur de México y Centroamérica.

Contacto: pacon_83@hotmail.com, iporraz@ecosur.mx

ORCID: 0000-0002-6424-5416 